\title{
Optimal ESS Scheduling considering Demand Response for Electricity Charge Minimization under Time of Use Price
}

\author{
Kyeong-hee Cho ${ }^{1}$, Seul-ki Kim ${ }^{1}$, Jong-yul Kim ${ }^{1}$, Eung-sang Kim ${ }^{1}$, Yun-su Kim ${ }^{1}$ and Chang-hee Cho ${ }^{1}$ \\ ${ }^{1}$ Smart Distribution Research Center \\ Korea Electrotechnology Research Institute \\ 12, Bulmosan-ro 10 beon-gil, Seongsan-gu, Changwon-si Gyeongsangnam-do (Korea) \\ Phone:+82-55-280-1365, FAX: +82-55-280-1339 \\ e-mail: kx1004xh@keri.re.kr, blksheep@keri.re.kr, jykim@keri.re.kr, eskim@keri.re.kr, ysk0822@keri.re.kr, \\ chcho@keri.re.kr
}

\begin{abstract}
A dependency of the world on electrical energy has been increasing according to development of industry. To meet increasing power demand, existing generators have been expanded or new generators have been installed continually. But currently, the social acceptance for installing a new plant is difficult due to electromagnetic effects on human body, environmental pollutions, and so on. Therefore supply is not, demand side management (DSM) is need. In recently, various methods of DSM have researched for a long time.

Among them, this paper suggests method of optimal ESS scheduling considering demand response (DR) for electricity charge minimization under time of use (TOU) price. The DR is considered as price based programs and incentive based programs.

In case study, load of a practical industrial customer was managed by the proposed DSM method. The simulation results show the effectiveness of the method.
\end{abstract}

\section{Key words}

Demand Side Management, Demand Response, Energy Storage System, Incentive Price, Time of Use price

\section{Introduction}

A dependency of the world on electrical energy has been increasing according to development of industry. To meet increasing power demand, existing generators have been expanded or new generators have been installed continually. But currently, the social acceptance for installing a new plant is difficult due to electromagnetic risk, social acceptance, an expensive cost, and so on. Because of these problems, demand side management (DSM) is becoming more important.

DSM is defined as an activity that is conducting to induce electricity user in a reasonable way[1]. A typical structure of DSM in the world is shown in Figure 1.

Like as this figure, demand response (DR) in Republic of Korea is divided into two types incentive based program and price based program. In incentive based program, participants contract with electric power company and receive the rewards when they reduce their customer baseline (CBL) during the event period. In price based program, when price is high, participants reduce their electricity usage, whereas they increase their electricity usage when price is low under time of use (TOU) price.

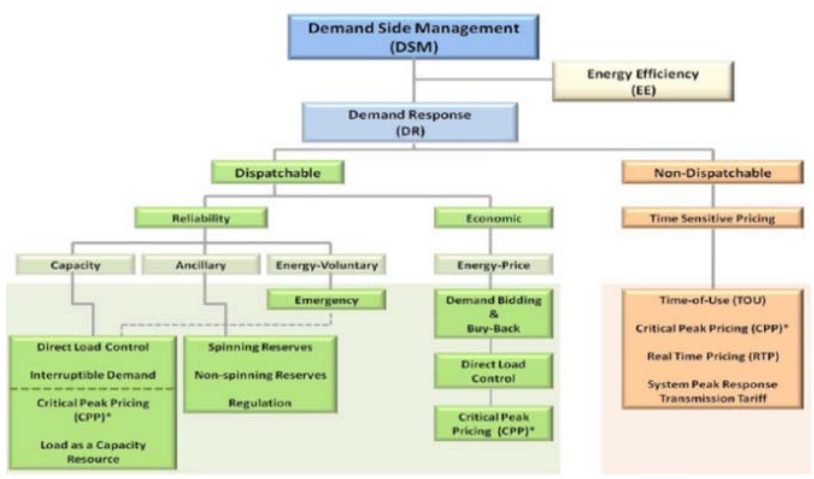

Fig. 1. Structure of Demand Side Management policy[2]

If an energy storage system (ESS) is used for DR to reduce the load during the event period or high price time, customers will reduce electricity price without inconvenience. If a customer has the ESS, an ESS operator needs to select a DR program to use and/or to determine a DR ratio to profit under the TOU price.

So, this paper presents a method finding optimal DR ratio when ESS will be scheduled for electricity charge minimization under TOU price.

In Chapter 2, DSM in Republic of Korea is determined in detail. In Chapter 3, a program formulation is described for simulation and an algorithm is shown. In case study, industrial customer's real load data was simulated by the proposed method. Results according to cases that varies DR ratio were compared with each other and show the optimal DR ratio.

\section{Demand Side Management}

Demand-side management (DSM) refers to various efforts of electric utilities to effectively meet electric power demand and supply at the minimum cost by modifying customers' patterns of electricity use. DSM activities in Republic of Korea consist of a number of 
load management programs to attain energy conservation and energy efficiency by changing the level and/or timing of customers' electricity demand by Korea electric power corporation (KEPCO) [2].

Also, demand response (DR) means demand adjustment program of advanced notice. Financial incentives are offered to the customers who reduce their demands at announced peak load periods. The incentive unit price of reducing power and the period terms are changed yearly by Korea power exchange (KPX) [3].

Electric rate policy by Ministry of knowledge economy in Republic of Korea adjusts the rate schedule from time to time, that is to say a TOU price. The rates we charge for electricity vary among the different classes of consumers, which principally consist of industrial, commercial, residential, educational, and agricultural consumers.

For example, hourly energy charge for industrial customer on weekdays is shown Fig. 2.

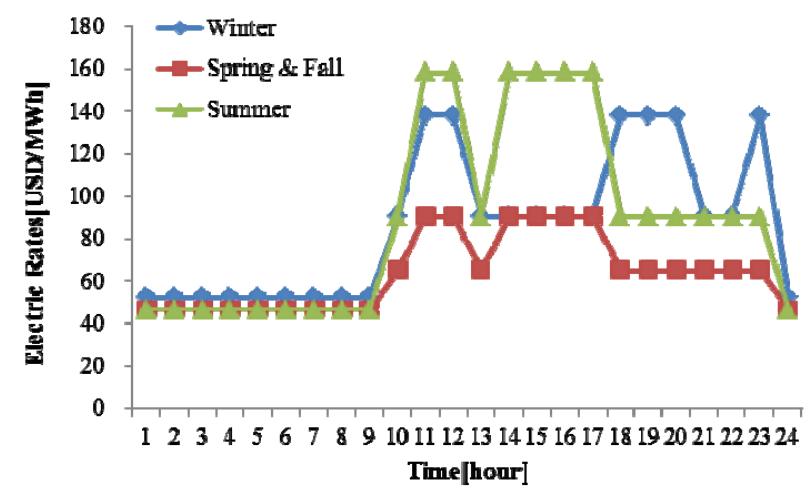

Fig. 2 Seasonally energy charge curves [USD/MWh] on weekdays for Industrial Service (A) II in Republic of Korea

Table I. - Time of use tariff schedules for industrial customer whose contract demand is smaller than 300 [kW] [2]

\begin{tabular}{|c|c|c|c|c|c|c|}
\hline \multirow{2}{*}{\multicolumn{2}{|c|}{ Classification }} & \multirow{2}{*}{$\begin{array}{c}\text { Demand } \\
\text { Charge } \\
\text { [USD/kW] }\end{array}$} & \multicolumn{4}{|c|}{ Energy Charge [USD/MWh] } \\
\hline & & & $\begin{array}{l}\text { Time } \\
\text { zone }\end{array}$ & $\begin{array}{c}\text { Summer } \\
{[7 \sim 8]}\end{array}$ & $\begin{array}{c}\text { Spring/Autumn } \\
{[3 \sim 6][9 \sim 10]}\end{array}$ & $\begin{array}{l}\text { Winter } \\
{[11 \sim 2]}\end{array}$ \\
\hline \multirow{6}{*}{$\begin{array}{l}\text { High } \\
\text { voltage } \\
(3.3 \sim \\
66 \mathrm{kV})\end{array}$} & \multirow{3}{*}{$\begin{array}{c}\text { Option } \\
1\end{array}$} & \multirow{3}{*}{5.16} & Off-peak & 48.6 & 48.6 & 54.4 \\
\hline & & & Mid-peak & 69.9 & 52.5 & 68.6 \\
\hline & & & On-peak & 93.6 & 65.7 & 88.0 \\
\hline & \multirow{3}{*}{$\begin{array}{c}\text { Option } \\
2\end{array}$} & \multirow{3}{*}{5.94} & Off-peak & 44.7 & 44.7 & 50.5 \\
\hline & & & Mid-peak & 65.9 & 48.6 & 64.7 \\
\hline & & & On-peak & 89.7 & 61.8 & 84.1 \\
\hline \multirow{6}{*}{$\begin{array}{c}\text { High } \\
\text { voltage } \\
(154 \mathrm{kV})\end{array}$} & \multirow{3}{*}{$\begin{array}{c}\text { Option } \\
1\end{array}$} & \multirow{3}{*}{4.78} & Off-peak & 46.4 & 46.4 & 52.0 \\
\hline & & & Mid-peak & 69.0 & 51.7 & 67.1 \\
\hline & & & On-peak & 92.5 & 64.6 & 86.0 \\
\hline & \multirow{3}{*}{$\begin{array}{c}\text { Option } \\
2\end{array}$} & \multirow{3}{*}{5.49} & Off-peak & 42.5 & 42.5 & 48.0 \\
\hline & & & Mid-peak & 65.1 & 47.8 & 63.2 \\
\hline & & & On-peak & 88.6 & 60.7 & 82.1 \\
\hline
\end{tabular}

\section{Program formulation}

When ESS (or several of ESS) is designed for DSM, economic analysis for various DR ratio cases should be accomplished under TOU price.

The algorithm is shown in Fig. 3 for calculating total benefit per year considering incentive based program and price based program. The program formulation for using this algorithm is described as follows:
First of all, input information of daily load data, TOU price data, ESS information, incentive period and incentive price are entered into the simulation program. This program is daily simulated from first day to last day of a year. Incentive based program percentage on target day (i) is selected and load is forecasted using past load data (A).

Then charging and discharging scheduling of ESS is optimized for minimization of electricity charge under TOU price (B).

An operation simulation that scheduling data is applied to real load (C) is performed. Electricity charge saved by TOU is estimated. According to incentive based program percentage, incentive by DR is calculated.

Then total benefit is calculated by adding electricity charge saving and incentive (D). Until $i$ becomes the last day, simulation is repeated by adding 1 to $i$. Finally, when $i$ becomes the last day, total benefit is calculated for a year.

In order to find optimal DR ratio, the simulation is repeated by moving DR percentage per year. Optimal DR ratio will be obtained by comparing benefits of various DR ratio cases.

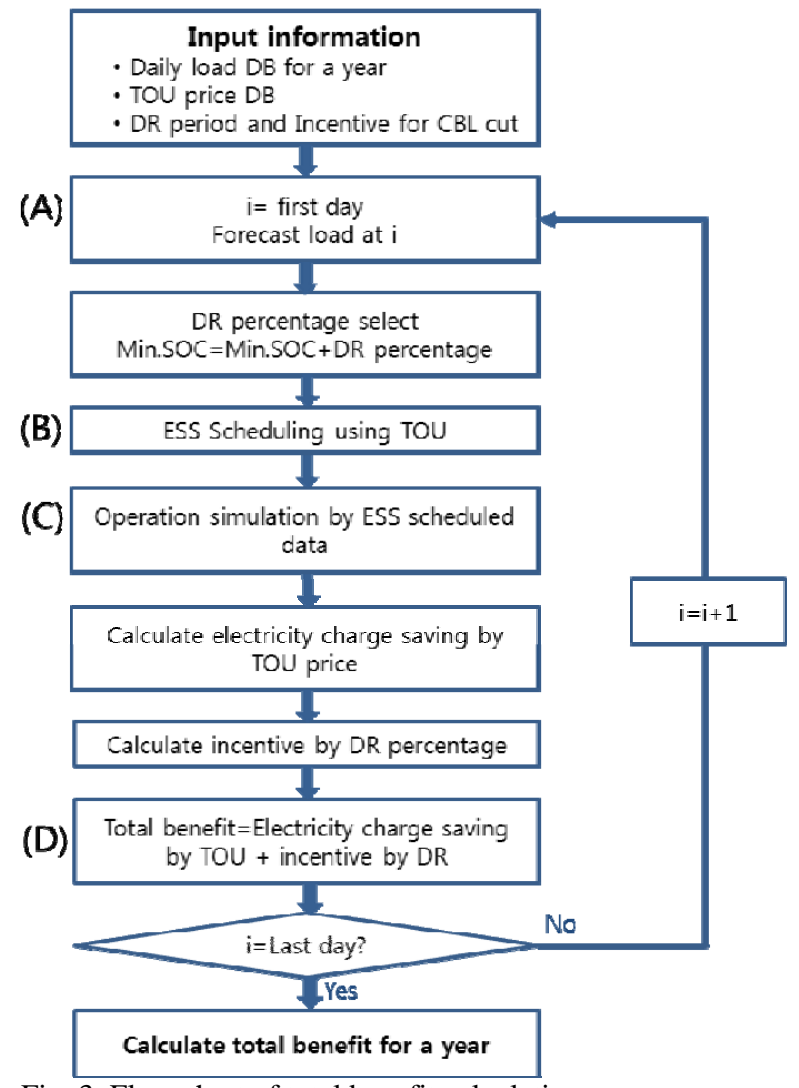

Fig. 3. Flow chart of total benefit calculation

\section{A. Load Forecasting}

For simulation of operation by using scheduled ESSs, load is forecasted by real load of industrial type customer. An adopted method is moving average model that is generally used for demand forecasting. Forecasted load at hour $t$ is calculated as (1).

$$
P_{t, d}=\frac{1}{n} \sum_{k=1}^{n} x_{t,(d-k)}
$$

Where, $\boldsymbol{P}_{\boldsymbol{t}, \boldsymbol{d}}$ : Forecasted power demand at hour $t$ day $d$ [kWh] $\boldsymbol{x}_{\boldsymbol{t}, \boldsymbol{d}}$ : Past real power demand at hour $t$ day $d$ [kWh] 
$t$ : Time [hour]

$n$ : Period considering of past power load data for forecasting [days]

\section{B. Optimization of Charging and Discharging of ESS}

For optimization of charging and discharging schedule of ESSs, commercial solver is used [4]. Variable and conditions are briefed as follows: Control variable is output of Power Conditioning System (PCS) connecting ESS. An object function is minimization of electicity charge. An electricity charge is calculated as follows:

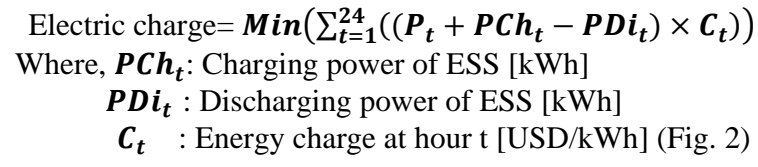

There are constraints 1) minimum and maximum of PCS's output, 2) ESS's state of charge (SOC), and 3) a point of common coupling's (PCC’s) power [5].

\section{Simulation of ESS Operation using scheduling optimization}

The optimal charging and discharging scheduling of ESS was applied to real load for testing operation. Then energy charge saving and base charge saving were calculated.

We assumed that operation is available when ESS scheduling by forecasted load is performed on real load. Also, we assumed that peak cut on forecased load is same as real load using same ESS scheduling.

\section{Benefit calculation}

Incentive benefit by Incentive based program is summation of static benefit and dynamic benefit. Static benefit is multiplication of contract capacity and static benefit price. Dynamic benefit is peak reduction capacity, electricity price, and reducing time.

Electricity charge saving by TOU price is electricity charge difference occurred by inserting to the system.

The electricity charge system applied to power companies is composed of the base cost and energy cost, while the amount of charge is determined by including the electric power public tasks evaluation and planning fund (3.7\%) and VAT $(10 \%)$ to the sum of the base cost and energy cost. The monthly and yearly electricity costs are then calculated as following equations (3) (5) [7].

$$
\text { Energy cost }\left[\frac{\mathrm{USD}}{\text { day }}\right]=\left[\sum_{\mathrm{t}=1}^{24}\left(P_{t} \times C_{t}\right)\right] \times 1.137
$$

Base cost $\left[\frac{\mathrm{USD}}{\text { year }}\right]=\sum_{m=1}^{12}\left[\right.$ Peak cut $[\mathrm{kW}] \times$ Base charge $\left.\left[\frac{U S D}{\mathrm{~kW}}\right]\right] \times 1.137$

$$
\begin{aligned}
& \text { Electric cost }\left[\frac{\mathrm{USD}}{\text { year }}\right]=\sum_{d=1}^{365}\left[{\text { Energy } \left.\text { cost }_{d}\right]+\sum_{m=1}^{12} \text { Base } \text { cost }}_{m}\right. \\
& \text { Electric charge saving }\left[\frac{\mathrm{USD}}{\mathrm{day}}\right]=\sum_{t=1}^{24}\left(\left(P D i_{t} \times C_{t}\right)-\left(P C h_{t} \times C_{t}\right)\right) \times 1.137
\end{aligned}
$$

Where, $t$ : hour

$$
\begin{aligned}
& \mathrm{d}: \text { day } \\
& \mathrm{m}: \text { month }
\end{aligned}
$$

Total benefit using ESS is summation of electricity charge saving under TOU price and incentive benefit by incentive based program.

\section{Simulation Results}

The system for simulation is shown in Fig.4. The system is connected to electric power company and demand response market for DSM.

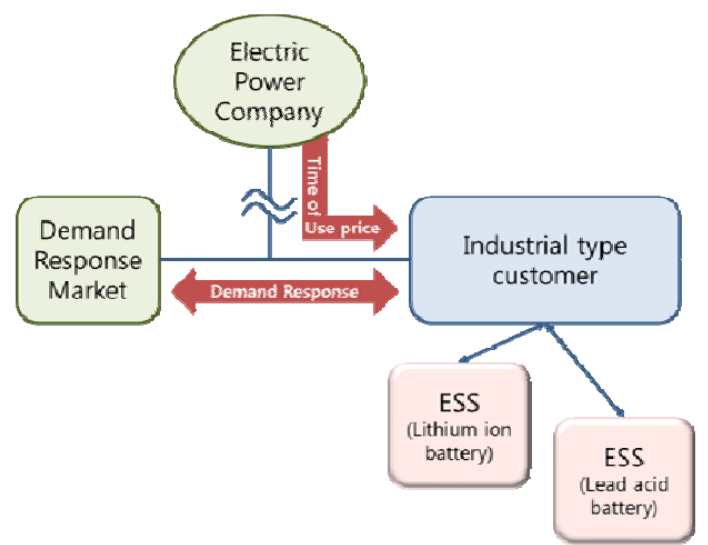

Fig. 4. Simulation system connecting electric power company using TOU and demand response market

According to algorithm (see Fig. 3), input data of industrial type customer's real load is saved and simulated. The customer seasonal load pattern is shown in Figure 5. Average forecasting load error by (1) is about 20\% during 2014.

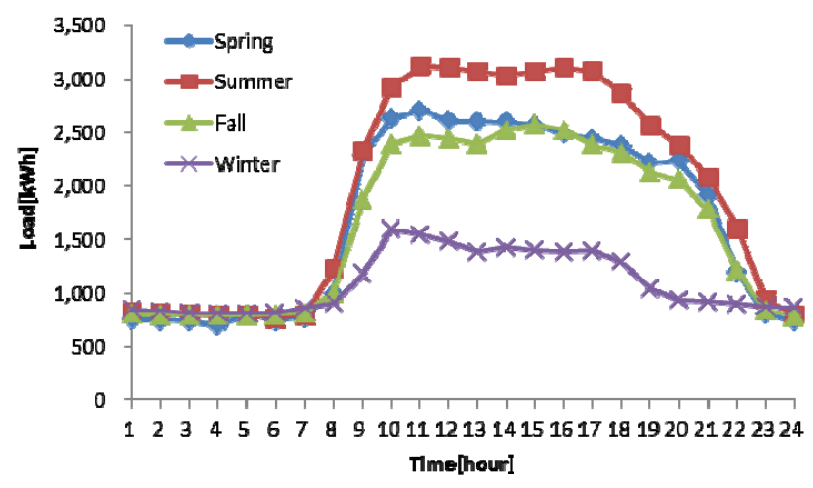

Fig. 5. Average load pattern of industrial type customer in weekday, 2014

First case is an optimal scheduling simulation of ESS whose SOC is limited from $20 \%$ to $100 \%$ and DR is $0 \%$. Incentive based program percentage is added to $10 \%$ per Case \# until $100 \%$. Electricity charge saving is calculated according to case and shown in Table II.

Table II. - Electricity charge saving according to case

\begin{tabular}{|c|c|c|c|c|}
\hline $\begin{array}{c}\text { Case } \\
\#\end{array}$ & $\begin{array}{c}\text { Peak } \\
\text { cut } \\
{[\mathrm{kW}]}\end{array}$ & $\begin{array}{c}\text { Energy } \\
\text { Charge } \\
\text { Saving } \\
\text { [USD] }\end{array}$ & $\begin{array}{c}\text { Base } \\
\text { Charge } \\
\text { Saving } \\
{[\text { USD] }}\end{array}$ & $\begin{array}{c}\text { Total } \\
\text { Saving } \\
\text { by TOU } \\
\text { [USD] }\end{array}$ \\
\hline 1 & 500 & $35,519.04$ & $46,892.80$ & $82,417.62$ \\
\hline 2 & 470 & $35,612.19$ & $44,079.23$ & $79,691.42$ \\
\hline 3 & 440 & $31,632.10$ & $41,265.66$ & $72,897.76$ \\
\hline 4 & 400 & $24,714.94$ & $37,514.24$ & $62,229.18$ \\
\hline 5 & 360 & $17,672.34$ & $33,762.81$ & $51,435.15$ \\
\hline 6 & 310 & $13,995.42$ & $29,073.53$ & $43,068.95$ \\
\hline 7 & 260 & $7,642.93$ & $24,384.25$ & $32,027.18$ \\
\hline 8 & 170 & $2,011.76$ & $15,943.55$ & $17,955.31$ \\
\hline 9 & 0 & 0 & 0 & 0 \\
\hline
\end{tabular}


We assume contract capacity unit price of static benefit is 34.8 [USD/kW] and electricity price is 124.5 [USD/MWh] and reducing time of dynamic benefit is 60 hours. Incentive benefits is calculated according to case and shown in Table III.

Table III. - Incentive benefits according to Case

\begin{tabular}{|r|r|r|r|r|}
\hline $\begin{array}{c}\text { Case } \\
\#\end{array}$ & $\begin{array}{c}\text { Contract } \\
\text { Capacity } \\
\text { [kW] }\end{array}$ & $\begin{array}{c}\text { Static } \\
\text { benefit } \\
\text { [USD] }\end{array}$ & $\begin{array}{c}\text { Dynamic } \\
\text { benefit } \\
\text { [USD] }\end{array}$ & $\begin{array}{c}\text { Total } \\
\text { benefit by } \\
\text { DR[USD] }\end{array}$ \\
\hline 1 & 0 & 0 & 0 & 0 \\
\hline 2 & 281 & $9,733.15$ & $2,085.67$ & $11,818.82$ \\
\hline 3 & 561 & $19,466.29$ & $4,171.35$ & $23,637.64$ \\
\hline 4 & 842 & $29,199.44$ & $6,257.02$ & $35,456.46$ \\
\hline 5 & 1,122 & $38,932.58$ & $8,342.70$ & $47,275.28$ \\
\hline 6 & 1,403 & $48,665.73$ & $10,428.37$ & $59,094.10$ \\
\hline 7 & 1,683 & $58,398.88$ & $12,514.04$ & $70,912.92$ \\
\hline 8 & 1,964 & $68,132.02$ & $14,599.72$ & $82,731.74$ \\
\hline 9 & 2,244 & $77,865.17$ & $16,685.39$ & $94,550.56$ \\
\hline
\end{tabular}

Results of Tables II and III are shown in Fig. 6. Total benefit was calculated by adding electricity charge saving and incentive benefits according to each case.

Optimal DR is Case 7 that incentive based program is $60 \%$. This graph describes that the case where ESS is scheduled for electricity charge minimization with incentive based program is better than the case without incentive based program.

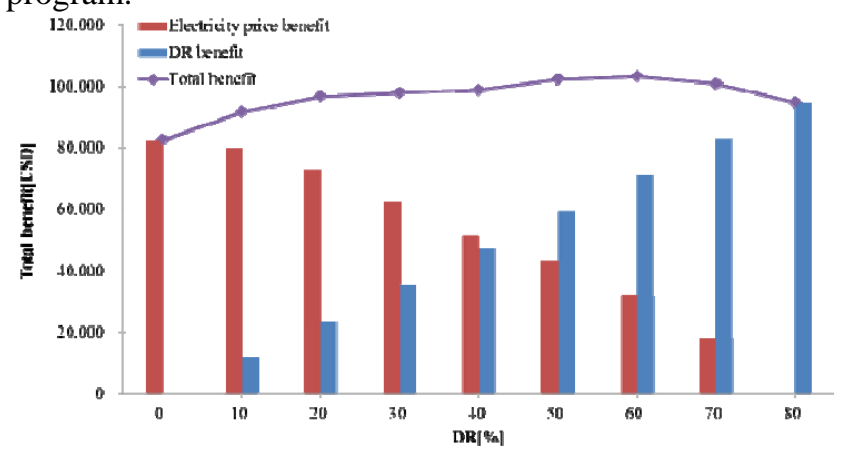

Fig. 6. Graph of total benefit using ESSs (lithium ion battery and lead acid battery) according to DR and TOU percentage

If reducing time of dynamic benefit is changed, the total benefit graph is changed as shown in Fig. 7. According to reducing time, optimal DR percentage is changed.

If contract capacity unit price of static benefit is changed, the total benefit graph is changed as shown Fig. 8. According to contract capacity unit price, optimal DR percentage is changed.

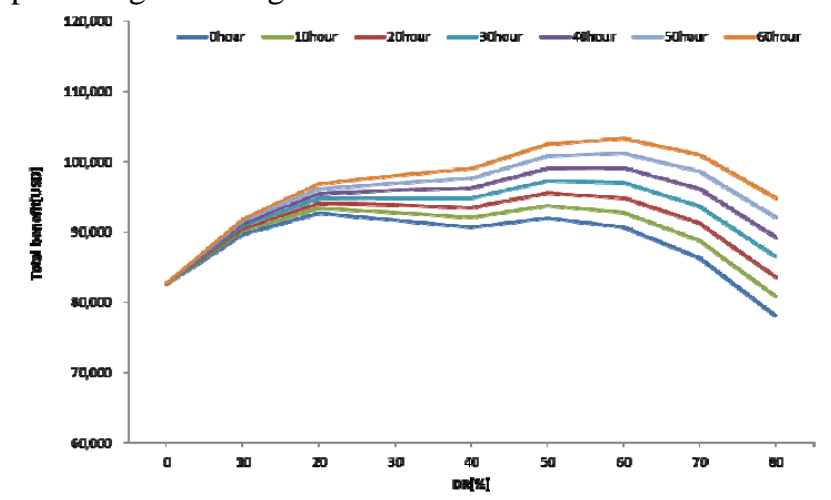

Fig. 7. Graph of total benefit like as Fig.6 changing ordering DR times

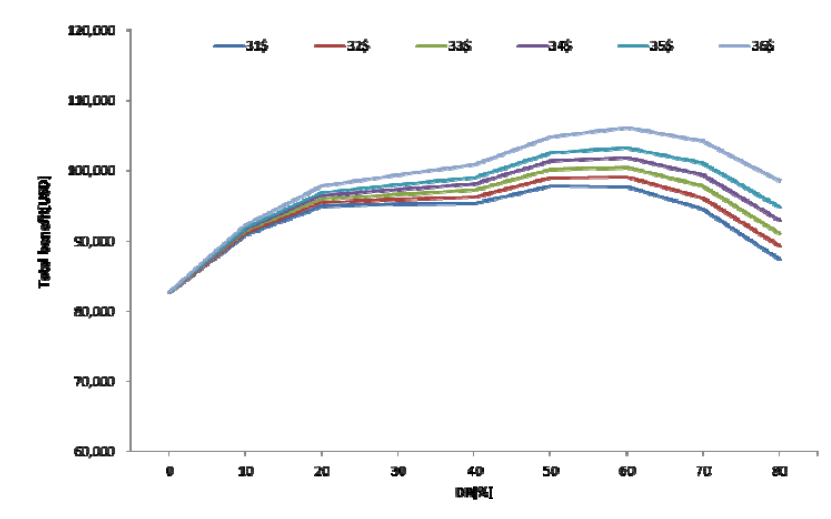

Fig. 8. Graph of total benefit like as Fig.6 changing contract capacity unit price

\section{Conclusion}

This paper presents the method of optimal ESS scheduling considering DR for electricity charge minimization under TOU price. The DR is considered as price based programs and incentive based programs.

In case study, load of a real industrial customer was managed by the proposed DSM method. The results are shown that the optimal case is Case 7 . This case is divided available capacity that $60 \%$ is incentive based program percentage for reducing CBL, $20 \%$ is charging and discharging under TOU price, and $20 \%$ is margin. Also simulation results show that the case where the ESS is scheduled for electricity charge minimization with incentive based program is better than the case without incentive based program. Of course, it is possible to meet the assumptions for operation and policy.

This simulation method can be used by customers who have ESSs and want to get the optimal DR combination.

\section{Acknowledgement}

This work was supported by the Power Generation \& Electricity Delivery Core Technology Program of the Korea Institute of Energy Technology Evaluation and Planning (KETEP) granted financial resource from the Ministry of Trade, Industry \& Energy, Republic of Korea (No.20143010011830).

\section{References}

[1] Demand Side Management customer portal, https://www. kepco.co.kr/dsm

[2] Korea Electric Power Corporation, “Guide to KEPCO’s Demand-Side Management”, May, 2013.

[3] Korea Power Exchange, http://www.kpx.or.kr/eng/index.do

[4] Frontline Solvers, http://www.solver.com

[5] K.-H. Cho, S.-K. Kim, E.-S. Kim, "Optimal Sizing of BESS for Customer Demand Management”, Journal of ICEE, Vol.1, 2014

[6] H.-J. Yun, "Status of international demand management policy”, KPX, 2014

[7] Korea Electric Power Corporation, http://cyber. kepco.co.kr

[8] Alireza Soroudi, Pierluigi Siani, Andrew Keane, "Optimal DR and ESS scheduling for Distribution Losses Payments Minimization Under Electricity Price Uncertainty”, IEEE Transactions on smart grid, Vol.7, No.1, January 2016. 